\title{
Use of High-Flow Nasal Cannula Oxygen Therapy in Subjects With ARDS: A 1-Year Observational Study
}

\author{
Jonathan Messika MD, Karim Ben Ahmed MD, Stéphane Gaudry MD, \\ Romain Miguel-Montanes MD, Cédric Rafat MD, Benjamin Sztrymf MD PhD, \\ Didier Dreyfuss MD, and Jean-Damien Ricard MD PhD
}

\begin{abstract}
BACKGROUND: Beneficial effects of high-flow nasal cannula (HFNC) oxygen on oxygenation and respiratory parameters have been reported in a small number of subjects with acute respiratory failure (ARF). We aimed to evaluate its effect in subjects with ARDS. METHODS: This was an observational single-center study. Prospectively obtained data were retrospectively analyzed. All patients admitted over $1 \mathrm{y}$ to a university hospital medicosurgical ICU were included. Classification was according to the highest ventilatory support required. HFNC indications were reviewed, and demographics, clinical characteristics, and course of subjects with ARDS according to intubation need were compared. RESULTS: Of 607 subjects admitted, 560 required ventilatory or oxygen support, among whom 180 received noninvasive ventilatory support. HFNC was used in 87 subjects and as first-line treatment in $\mathbf{5 1}$ subjects (29\% of first-line noninvasively treated subjects), $\mathbf{4 5}$ of which had ARDS $\left(\mathrm{P}_{\mathrm{aO}_{2}} / \mathrm{F}_{\mathrm{IO}_{2}}\right.$ of $137 \mathrm{~mm} \mathrm{Hg} ; 22 \mathrm{men}, 57.9 \mathrm{y}$ of age). Pneumonia accounted for $82 \%$ of ARDS causes. The intubation rate in these subjects was $40 \%$. Higher Simplified Acute Physiology Score II (SAPS II; 46 vs 29, $P=.001)$, occurrence of additional organ failure $(76 \%$ vs $26 \%$, $P=.002)$, mainly hemodynamic $(50 \%$ vs $7 \%, P=.001)$ or neurological $(22 \%$ vs $0, P=.01)$, and trends toward lower $\mathrm{P}_{\mathrm{aO}} / \mathrm{F}_{1 \mathrm{O}_{2}}$ and higher breathing frequency after $\mathrm{HFNC}$ initiation were evidenced in subjects who failed HFNC. Higher SAPS II scores were associated with HFNC failure in multivariate analysis. CONCLUSIONS: In daily care, over one fourth of subjects requiring noninvasive ventilatory support were treated via HFNC, with a high success rate in subjects with severe ARDS. We conclude that HFNC may be considered as first-line therapy in ARF, including patients with ARDS. Key words: acute respiratory failure; high flow; oxygen therapy; noninvasive ventilation; outcome. [Respir Care 2015;60(2):162-169. ( 2015 Daedalus Enterprises]
\end{abstract}

\section{Introduction}

Acute respiratory failure (ARF) requiring mechanical ventilation is one of the major reasons for ICU admission. To limit hazards associated with invasive mechanical ven-

Drs Messika, Ben Ahmed, Gaudry, Miguel-Montanes, Rafat, Dreyfuss, and Ricard are affiliated with the Assistance Publique-Hôpitaux de Paris, Hôpital Louis Mourier, Service de Réanimation Médico-Chirurgicale, Colombes, France. Drs Messika, Gaudry, Dreyfuss, and Ricard are also affiliated with the Institut National de la Santé et de la Recherche Médicale, Infection, Antimicrobiens, Modélisation, Evolution, Unité Mixte de Recherche 1137, Paris, France and with Université Paris Diderot, Infection, Antimicrobiens, Modélisation, Evolution, Unité Mixte de Recherche 1137, Sorbonne Paris Cité, Paris, France. Dr Sztrymf is affiliated with the Assistance Publique-Hôpitaux de Paris, Hôpital Antoine Béclère, Service de Réanimation Médico-Chirurgicale, Clamart, France. tilation, noninvasive ventilation (NIV) is increasingly used as an efficient alternative, especially in acute-on-chronic respiratory failure. Regarding de novo ARF, results with NIV are more mitigated, ${ }^{1}$ although some reports have shown benefits in acute lung injury and subjects with ARDS. ${ }^{2}$ In addition, several drawbacks with NIV, such as patient

\footnotetext{
Dr Ricard has disclosed a relationship with Fisher \& Paykel. The other authors have disclosed no conflicts of interest.

Correspondence: Jean-Damien Ricard MD PhD, Service de Réanimation Médico-Chirurgicale, Hôpital Louis Mourier, 92700 Colombes, France. E-mail: jean-damien.ricard@1mr.aphp.fr.
}

DOI: $10.4187 /$ respcare. 03423 
intolerance and discomfort, ${ }^{3}$ lead to its early interruption in up to $22 \%$ of patients. ${ }^{4}$ Finally, with the exception of hypercapnic encephalopathy, NIV cannot be used in patients with neurological impairment. In these situations, conventional oxygen therapy is the only option before tracheal intubation. However, additional oxygen administration also has its caveats. These include limited flow, imprecise and limited $\mathrm{F}_{\mathrm{IO}_{2}}$, intolerance due to dryness of the inspired gases, and claustrophobia due to the face mask. ${ }^{5}$ A new technique has emerged from the neonatal field (where it has shown very promising results ${ }^{6}$ ) that counteracts most of the drawbacks associated with conventional oxygen therapy 7,8 : high-flow nasal cannula (HFNC) oxygen consists of the delivery of high $(50-60 \mathrm{~L} / \mathrm{min})$, heated, and humidified oxygen flow at a chosen $\mathrm{F}_{\mathrm{IO}_{2}}$ via a widebore nasal cannula. This high oxygen flow allows inspiratory flow increases in hypoxemic patients to be monitored.

See the Related Editorial on Page 307

Oxygen dilution is therefore minimized, and the delivered $\mathrm{F}_{\mathrm{IO}_{2}}$ is close to the set $\mathrm{F}_{\mathrm{IO}_{2}} \cdot{ }^{7}$ Physiological effects of HFNC include nasopharyngeal carbon dioxide washout, decrease in inspiratory resistance, alleviation of dyspnea, and reduced work of breathing. ${ }^{7,9}$ Recent reports have highlighted the beneficial effects of HFNC in ICU patients with hypoxemic ARF. ${ }^{10-12}$ Similar effects have been reported in the emergency department. ${ }^{13}$ Not only does HFNC rapidly alleviate respiratory distress in these patients, but sustained effects have been reported, after patients were managed for several days with this technique. ${ }^{10,11,14}$ Although these studies showed positive results, the applicability and generalization of this technique remain unclear because studies are limited to the very short-term impact of HFNC, ${ }^{15}$ subjects with mild-to-moderate respiratory failure, ${ }^{12}$ and a small number of subjects with potential selection bias. ${ }^{10,11}$ Indications for HFNC are not as well defined as for NIV, ranging from palliative situations ${ }^{14,16,17}$ to pulmonary infections ${ }^{18}$ or cardiac failure. ${ }^{19}$ There is no precise view on this technique's exact place in the therapeutic arsenal of ARF, in particular regarding the most severe patients, those with ARDS. In addition, few studies have compared NIV and HFNC. To date, the only study comparing HFNC with NIV was performed in subjects with mild respiratory failure ${ }^{12}$; a large randomized controlled trial in more severe patients has just been completed (FLORALI trial, ClinicalTrials.gov identifier NCT01320384). We thus sought to answer the following questions: in a general medicosurgical ICU, outside a research protocol, how effective is HFNC in treating patients with ARDS; how often is HFNC used in comparison with other forms of ventilatory support (invasive and noninvasive ventilation) using conventional face mask and nasal prong

\section{QUICK LOOK}

\section{Current knowledge}

Heated and humidified oxygen via high-flow nasal cannula reduces ventilatory requirements by flushing the anatomical dead space and improves oxygenation by meeting inspiratory flow demands. Heat and humidity allow the high flows to be tolerated and improve patient comfort.

\section{What this paper contributes to our knowledge}

Of one fourth of subjects requiring noninvasive ventilatory support for acute respiratory failure, heated and humidified high-flow oxygen prevented intubation in half. Heated high-flow oxygen via nasal cannula can be employed for first-line treatment of ARDS in patients who do not require emergent intubation.

oxygen delivery; and with which indications and success rate?

\section{Methods}

\section{Study Design}

This was an observational, 1-y, single-center study in a 12-bed university hospital medicosurgical ICU. Every incoming patient was prospectively integrated in a large multi-center database (CUB-Réa) that includes usual demographics, past and present medical history, comorbidities, anamnestic information, and reason for and use of any ventilatory support as well as its precise duration. Clinical and biological data are included in this database.

\section{Ethics}

The ethics committee of the Société de Réanimation de Langue Française (French Society of Intensive Care Medicine) approved this study (number 12-363). Informed consent was not requested due to the purely observational design of our study and the routine use of HFNC in our unit. However, subjects and/or families were informed of the study, its purpose, and objectives.

\section{Ventilatory Support Classification}

To determine how often HFNC was used in comparison with other forms of ventilatory support, subjects were classified according to the highest support received: (1) intubation and mechanical ventilation before ICU admission (intubation was performed in a prehospital setting, oper- 


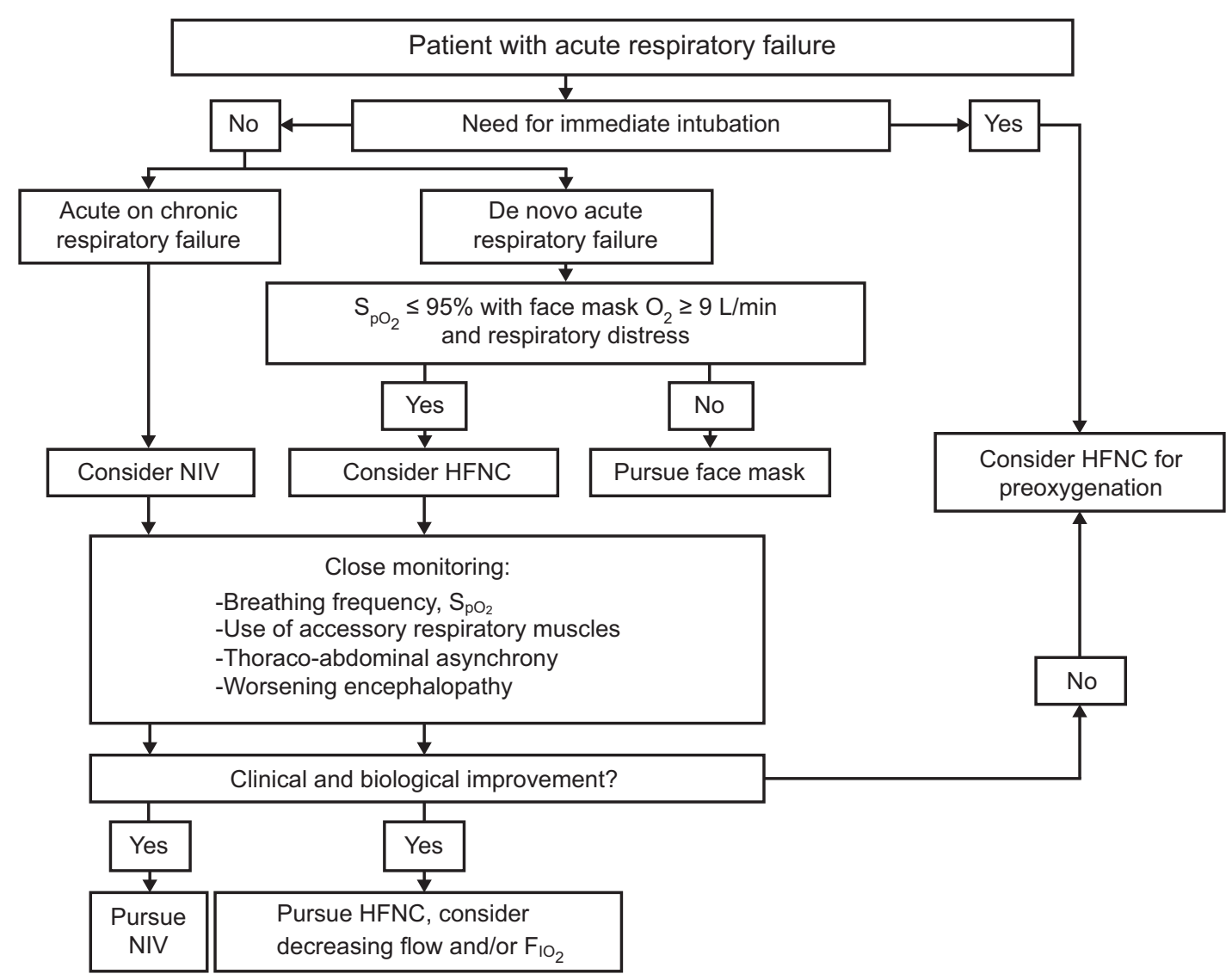

Fig. 1. Management protocol of subjects with acute respiratory failure (ARF) used in our unit. This figure illustrates the routine protocol applied to patient management in case of ARF. High-flow nasal cannula (HFNC) is the first-line treatment used in de novo ARF. NIV = non invasive ventilation.

ating room, or emergency department of a referral hospital); (2) immediate $(<6 \mathrm{~h})$ or (3) delayed ( $>6 \mathrm{~h})$ intubation after ICU admission; (4) intubation following HFNC or NIV (defining HFNC or NIV failure); (5) exclusive use of NIV; (6) use of HFNC; (7) combination of NIV and HFNC; (8) conventional oxygen delivery via a face mask ( $\geq 6 \mathrm{~L} / \mathrm{min}$ ) or (9) nasal prongs $(<6 \mathrm{~L} / \mathrm{min})$; or $(10)$ no oxygen at all.

\section{Routine Management of ARF}

In our unit, management of ARF includes the use of tracheal intubation, NIV, HFNC, and conventional oxygen therapy delivered via high- $\mathrm{F}_{\mathrm{IO}_{2}}$, non-rebreathing, bag reservoir face masks.

All subjects were managed according to our protocol (Fig. 1). We follow classic indications for tracheal intubation, including respiratory arrest, respiratory pauses with loss of consciousness, psychomotor agitation making nursing care impossible and requiring sedation, hemodynamic instability despite vasopressor administration and with systolic arterial pressure below $70 \mathrm{~mm} \mathrm{Hg}, \mathrm{P}_{\mathrm{aO}_{2}}$ below $45 \mathrm{~mm} \mathrm{Hg}$, loss of consciousness, or worsening encepha- lopathy. ${ }^{20}$ In the absence of indications for immediate tracheal intubation, NIV is used in case of acute-on-chronic hypercapnic respiratory failure. HFNC is used in de novo respiratory failure when patients require $>9 \mathrm{~L} / \mathrm{min}$ oxygen with a conventional face mask to maintain $\mathrm{S}_{\mathrm{pO}_{2}}$ at $>92 \% .{ }^{10}$ Patients are closely monitored to detect muscle fatigue, desaturation despite full use of the device, or any other signs indicating the need for urgent tracheal intubation.

\section{Oxygen Delivery}

The HFNC device (Optiflow, Fisher \& Paykel, Auckland, New Zealand) consists of an air-oxygen blender with adjustable $\mathrm{F}_{\mathrm{IO}_{2}}(0.21-1.0)$ that delivers a modifiable gas flow (up to $60 \mathrm{~L} / \mathrm{min}$ ) to a heated chamber (MR 850 passover humidifier, Fisher \& Paykel), where the gas is heated and humidified. The gas mixture is then routed through a high-performance circuit (RT 310, Fisher \& Paykel) to be delivered at $37^{\circ} \mathrm{C}$ containing $44 \mathrm{mg} \mathrm{H}_{2} \mathrm{O} / \mathrm{L}$ to the patient via short, wide-bore binasal prongs. Conventional oxygen was given through a high- $\mathrm{F}_{\mathrm{IO}_{2}}$, non-rebreathing face mask (Hudson RCI/Teleflex Medical, Research Triangle Park, North Carolina). 


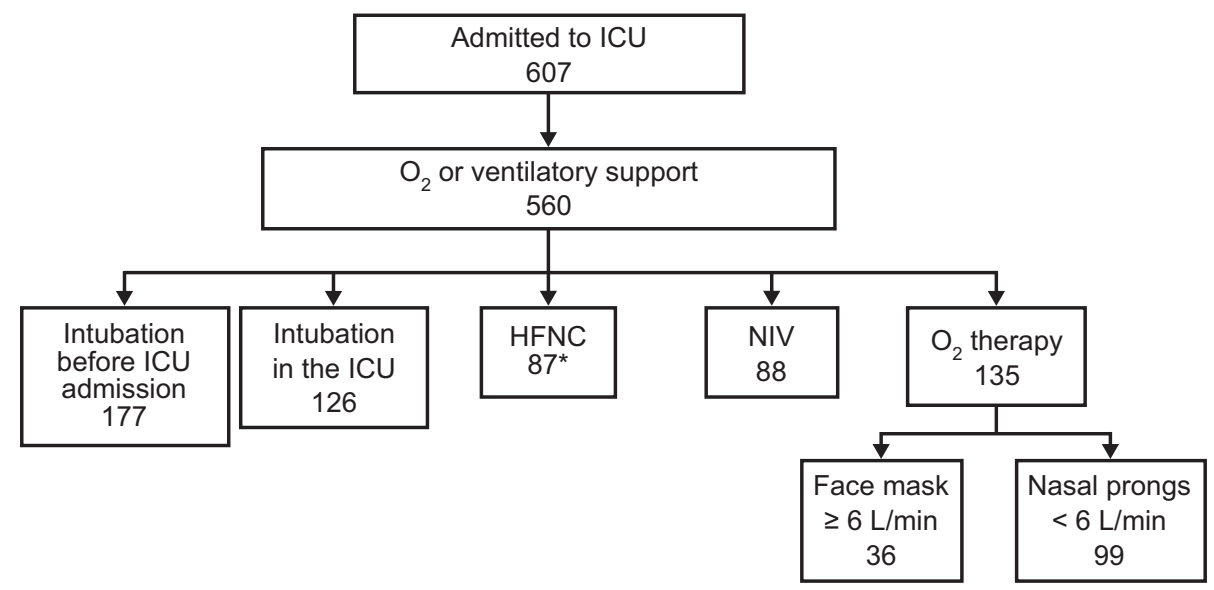

Fig. 2. Subject flow chart of all admissions during the study period. Multiple oxygenation techniques may have been used in a single subject. Overall, high-flow nasal cannula (HFNC) was the first-line noninvasive treatment for $29 \%$ of respiratory failure subjects: 51 (first-line $\mathrm{HFNC}) /\left[51\right.$ (first-line HFNC) +88 (NIV) +36 (oxygen mask)] $=29 \%$. ${ }^{*}$ Detailed HFNC use of these 87 subjects is shown in Figure 3 . NIV = noninvasive ventilation.

\section{Definition of ARDS in Nonventilated Subjects}

The new definition of ARDS requires that arterial blood gases be performed under at least $5 \mathrm{~cm} \mathrm{H}_{2} \mathrm{O}$ positive pressure to assess $\mathrm{P}_{\mathrm{aO}} / \mathrm{F}_{\mathrm{IO}_{2}}$ and qualify ARDS severity. ${ }^{21}$ However, the natural history of ARDS does not begin immediately upon intubation, and many patients require intubation precisely because of ARDS, which is officially confirmed with $\mathrm{P}_{\mathrm{aO}_{2}} / \mathrm{F}_{\mathrm{IO}_{2}}$ measured after initiation of mechanical ventilation with at least $5 \mathrm{~cm} \mathrm{H}_{2} \mathrm{O}$ positive pressure. Thus, all subjects who had a history of ARF within 1 week of a known clinical insult, with $\mathrm{P}_{\mathrm{aO}_{2}} / \mathrm{F}_{\mathrm{IO}_{2}}$ below $300 \mathrm{~mm} \mathrm{Hg}$ and bilateral opacities evidenced on chest $\mathrm{x}$-ray not fully explained by cardiac failure or fluid overload, ${ }^{21}$ were considered to have ARDS.

\section{Statistical Analysis}

Data were analyzed with Prism 4 (GraphPad Software, San Diego, California). Subjects' demographics, clinical variables, and laboratory findings were expressed as median (interquartile range). Subjects' continuous variables were compared according to failure or success of HFNC using the Mann-Whitney $U$ test or the paired $t$ test when appropriate. The chi-square test was used when comparing proportions. To identify factors associated with HFNC failure, we selected variables by univariate analysis $(P<.1)$ and entered them in a stepwise logistic regression analysis. $P<.05$ was considered statistically significant.

\section{Results}

Between September 2010 and August 2011, 607 consecutive subjects were admitted to our ICU, with a median age $62(46-75)$ y and a median Simplified Acute Physiology Score II (SAPS II) score of 39 (27-53).

Figure 2 details the ventilatory support received by the subjects. Eighty-seven subjects received HFNC at least once during their ICU stay; of these, 51 subjects received HFNC as first-line treatment for respiratory failure. NIV was used as first-line treatment for respiratory failure in 88 subjects; of these, 76 subjects received NIV as the highest ventilatory support. Oxygen therapy of $\geq 6 \mathrm{~L} / \mathrm{min}$ was necessary for 36 subjects. Overall, HFNC was the firstline noninvasive treatment for $29 \%$ of subjects with respiratory failure (see Fig. 2 for details). Of the subjects requiring invasive ventilation after ICU admission $(n=126)$, the majority were intubated within the first $6 \mathrm{~h}$ of admission $(n=88,70 \%)$. Finally, 177 subjects $(30 \%)$ were intubated before ICU admission.

\section{HFNC Subjects}

Figure 3 depicts the different uses of HFNC. The main use of HFNC was first-line treatment of de novo ARF in 51 subjects; of these, 45 subjects met ARDS criteria. HFNC was used at all stages of ARF management from preoxygenation to postextubation, including palliative ventilatory support.

\section{Characteristics of ARDS Subjects}

Forty-five subjects met ARDS criteria, with 33\% considered as severe ARDS $\left(\mathrm{P}_{\mathrm{aO}_{2}} / \mathrm{F}_{\mathrm{IO}_{2}}<100 \mathrm{~mm} \mathrm{Hg}\right), 38 \%$ as moderate $\left(\mathrm{P}_{\mathrm{aO}_{2}} / \mathrm{F}_{\mathrm{IO}_{2}}\right.$ of $\left.100-200 \mathrm{~mm} \mathrm{Hg}\right)$, and $29 \%$ as mild $\left(\mathrm{P}_{\mathrm{aO}_{2}} / \mathrm{F}_{\mathrm{IO}_{2}}\right.$ of $\left.200-300 \mathrm{~mm} \mathrm{Hg}\right)$ (Table 1). Median breathing frequency was $34(30-40)$ breaths/min, with a radiological extent of 3 (2-4) quadrants. The SAPS II 


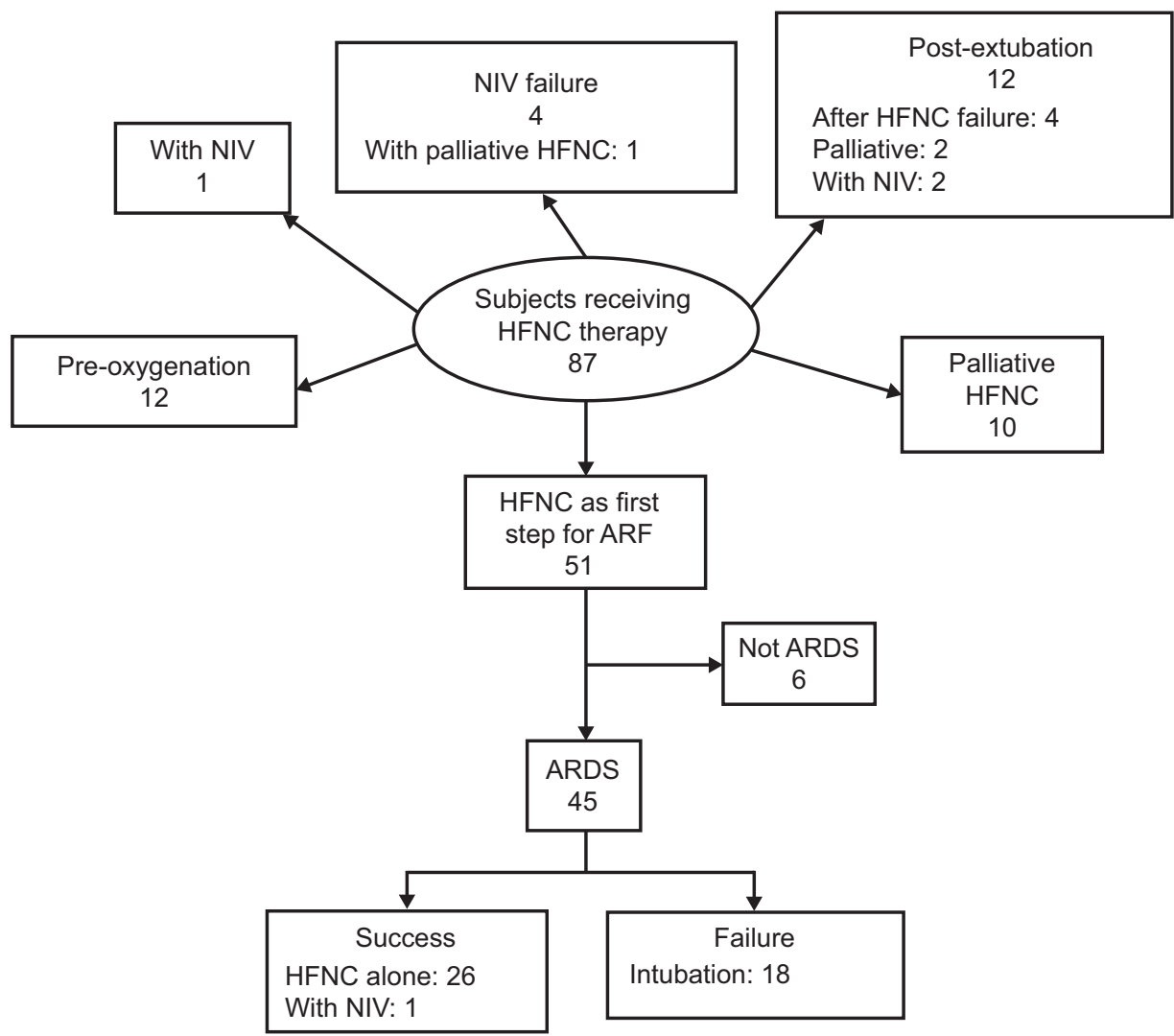

Fig. 3. Eighty-seven subjects had high-flow nasal cannula (HFNC) therapy at least once during ICU stay. Detailed indications are shown. $\mathrm{ARF}=$ acute respiratory failure, NIV $=$ noninvasive ventilation .

score was 36 (24-44). Median $\mathrm{P}_{\mathrm{aO}} / \mathrm{F}_{\mathrm{IO}_{2}}$ was 137 (88.5208.5), and 44\% of subjects had at least one additional organ failure. Etiology of ARDS was mainly acute infectious pneumonia ( $80 \%)$, followed by drug-induced ARDS (11\%) and acute lung injury of extrapulmonary origin (9\%).

\section{Initial Settings}

$\mathrm{F}_{\mathrm{IO}_{2}}$ was initially set at the highest level (1.0) for $73 \%$ of subjects. In all but 2 subjects, $\mathrm{F}_{\mathrm{IO}_{2}}$ was set at $>0.5$. Initial oxygen flow was $60 \mathrm{~L} / \mathrm{min}$.

\section{Outcome of ARDS Subjects}

In this group of very severely hypoxemic subjects (worst $\mathrm{P}_{\mathrm{aO}_{2}} / \mathrm{F}_{\mathrm{IO}_{2}}$ of $\left.108.6[73-137.1] \mathrm{mm} \mathrm{Hg}\right)$, only 18 subjects required secondary intubation $(40 \%)$ and were thus classified as having failed HFNC. Reasons for intubation included worsening of hypoxemia (13 subjects, $72 \%$ ), onset of hemodynamic (4 subjects, 22\%), or neurologic failure (one subject, 6\%). These subjects had a significantly higher SAPS II score (46 [29-61.5] vs 29 [22-37], $P=.001$ ), mostly due to dysfunction of one or more organs ( $76 \%$ vs
$26 \%, P=.002)$, such as hemodynamic (50\% vs $7 \%$, $P=.001)$ or neurological (22\% vs $0 \%, P=.01)$ failure. HFNC tended to be more frequently discontinued before $24 \mathrm{~h}$ in these subjects (67\% vs $37 \%, P=.051$ ) since they were intubated. There was a trend toward lower $\mathrm{P}_{\mathrm{aO}_{2}} / \mathrm{F}_{\mathrm{IO}_{2}}$ after initiation of HFNC in subjects who ultimately required intubation compared with those who did not (115.3 [84-177.1] vs 145.3 [97.5-223.5], $P=.26)$ and a significant difference in the lowest $12-\mathrm{h}_{\mathrm{aO}_{2}} / \mathrm{F}_{\mathrm{IO}_{2}}(91.5[64-$ 129.5] vs 124 [93-217], $P=.02$ ). Eighteen subjects who required tracheal intubation were pre-oxygenated with HFNC. Factors associated with intubation requirement in ARDS are detailed in Table 2. Univariate analysis identified SAPS II, hemodynamic failure, and the lowest 12-h $\mathrm{P}_{\mathrm{aO}_{2}} / \mathrm{F}_{\mathrm{IO}_{2}}$ to be associated with intubation. In the multivariate analysis, only the SAPS II score was significantly associated with intubation requirement.

\section{Discussion}

This observational study aimed to describe ARDS management with HFNC, thus constituting to date the largest series of consecutive subjects with ARDS treated via HFNC 
Table 1. Demographics, Clinical Features, and Outcomes of Subjects With ARDS Treated via HFNC

\begin{tabular}{|c|c|c|c|c|}
\hline & $\begin{array}{l}\text { All Subjects With ARDS } \\
\qquad(N=45)\end{array}$ & $\begin{array}{l}\text { HFNC Success } \\
\quad(n=27)\end{array}$ & $\begin{array}{l}\text { HFNC Failure } \\
\quad(n=18)\end{array}$ & $P$ \\
\hline Age, median (IQR), y & $57.9(38.7-74.2)$ & $46.1(39-75.2)$ & $62.8(37.1-72.6)$ & .89 \\
\hline Males, $n(\%)$ & $22(49)$ & $13(48)$ & $9(50)$ & .86 \\
\hline At least one comorbid condition, $n(\%)$ & $27(60)$ & $14(52)$ & $14(78)$ & .08 \\
\hline Chronic heart failure & $5(11)$ & $2(7)$ & $3(17)$ & .33 \\
\hline COPD & $5(11)$ & $3(11)$ & $2(11)$ & $>.99$ \\
\hline Neurodegenerative disease & $4(9)$ & $3(11)$ & $1(6)$ & .52 \\
\hline \multicolumn{5}{|l|}{ Reason for HFNC oxygen therapy, $n(\%)$} \\
\hline Pneumonia & $36(80)$ & $23(85)$ & $13(72)$ & .44 \\
\hline ALI of extra-pulmonary origin & $4(9)$ & $2(7)$ & $2(11)$ & .67 \\
\hline Toxic ARDS & $5(11)$ & $2(7)$ & $3(17)$ & .33 \\
\hline At least one associated organ failure, $n(\%)$ & $20(44)$ & $7(26)$ & $13(76)$ & .002 \\
\hline Hemodynamic & $11(24)$ & $2(7)$ & $9(50)$ & .001 \\
\hline Kidney & $12(27)$ & $6(22)$ & $6(33)$ & .59 \\
\hline Neurological & $4(9)$ & 0 & $4(22)$ & .01 \\
\hline SAPS II score, median (IQR) & $36(24-44)$ & $29(22-37)$ & $46(29-61.5)$ & .001 \\
\hline $\begin{array}{l}\text { Highest breathing frequency, median (IQR), } \\
\text { breaths/min }\end{array}$ & $34(30-40)$ & $33(30-40)$ & $37(29-40)$ & .57 \\
\hline Initial $\mathrm{P}_{\mathrm{aO}_{2}} / \mathrm{F}_{\mathrm{IO}_{2}}$, median (IQR) & $137(88.5-208.5)$ & $145.3(97.5-223.5)$ & $115.3(84-177.1)$ & .26 \\
\hline Lowest $\mathrm{P}_{\mathrm{aO}_{2}} / \mathrm{F}_{\mathrm{IO}_{2}}$, median (IQR) & $108.6(73-137.1)$ & $124(93-217)$ & $91.5(64-129.5)$ & .02 \\
\hline HFNC oxygen therapy duration of $<24 \mathrm{~h}, n(\%)$ & $22(49)$ & $10(37)$ & $12(67)$ & .05 \\
\hline Duration of therapy, median (IQR), $\mathrm{h}$ & $24(12.5-50)$ & $32(16-53)$ & $20(12-31)$ & .16 \\
\hline ICU stay, median (IQR), d & $4(3-12.5)$ & $3(2-5)$ & $13.5(5.5-19)$ & .001 \\
\hline Alive at ICU discharge, $n(\%)$ & $35(78)$ & $26(96)$ & $9(50)$ & .001 \\
\hline Alive at day $28, n(\%)$ & $33(71)$ & $24 *(89)$ & $9(50)$ & .003 \\
\hline $\begin{array}{l}{ }^{*} \text { Two missing data } \\
\text { IQR = interquartile range } \\
\text { HFNC = high-flow nasal cannula } \\
\text { ALI = acute lung injury } \\
\text { SAPS II = Simplified Acute Physiology Score II }\end{array}$ & & & & \\
\hline
\end{tabular}

Table 2. Univariate and Multivariate Analyses of Variables Associated With Intubation Need

\begin{tabular}{lcccc}
\hline \hline & \multicolumn{2}{c}{ Univariate Analysis } & & \multicolumn{1}{c}{ Multivariate Analysis } \\
\cline { 2 - 3 } & Odds Ratio $(\mathrm{CI} 95 \%)$ & $P$ & Odds Ratio (CI 95\%) \\
\hline Associated hemodynamic failure & $12.5(2.26-69.2)$ & .004 & $3.90(0.51-30.05)$ \\
SAPS II & $1.095(1.03-1.16)$ & .002 & $1.08(1.01-1.16)$ \\
Lowest $\mathrm{P}_{\mathrm{aO}_{2}} / \mathrm{F}_{\mathrm{IO}_{2}}$ & $0.98(0.96-0.99)$ & .02 & $.0 .98(0.95-1.01)$
\end{tabular}

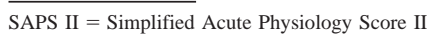

with complete follow-up. Furthermore, it captures real-life daily use of HFNC in a general medicosurgical ICU. We can summarize our results as follows: (1) HFNC was used in 45 subjects with ARDS, of whom only $40 \%$ required secondary intubation; (2) a large variety of causes of ARF requiring ICU admission were treated by HFNC, but pneumonia accounted for $82 \%$ of our HFNC use; and (3) the presence of additional organ failure, mainly hemodynamic or neurological, was associated with a higher HFNC failure rate. Given the increasing use of HFNC in adult patients, ${ }^{7,8}$ our results have direct clinical applications.
The precise use of HFNC in daily practice, outside research protocols, remains unknown. Case reports and studies with a small number of subjects have been published, but no longitudinal data on consecutive patients are available. We were surprised to find that almost one third of our subjects that required any respiratory support of $\geq 6 \mathrm{~L} / \mathrm{min}$ oxygen received HFNC. Importantly, HFNC was used at all other stages of respiratory support, from pre-oxygenation for intubation to postextubation and palliative oxygen therapy.

To date, ICU management of respiratory failure is the indication that has received the greatest attention. ${ }^{10-12,15,18}$ 
Here, we were interested in assessing HFNC use in subjects with ARDS in a fashion similar to that used by Antonelli et $\mathrm{al}^{2}$ to investigate NIV use in these subjects. We did not select a priori breathing frequency as an ARDS criterion. However, most of our subjects (80\%) had a breathing frequency of $\geq 30$ breaths/min, which was the threshold chosen by Antonelli et al ${ }^{2}$ to initiate NIV in their study. $\mathrm{P}_{\mathrm{aO}_{2}} / \mathrm{F}_{\mathrm{IO}_{2}}$ was in the same range of severity, between 115 and $140 \mathrm{~mm} \mathrm{Hg}$. Interestingly, our $40 \%$ intubation rate is very similar although slightly lower than their rate of $46 \%$, which may be attributed to a greater proportion of subjects with septic shock in their study. This is consistent with the results of Rello et al, ${ }^{18}$ who reported a $55 \%$ rate in a small cohort of subjects with H1N1. They found that subjects with HFNC who were on vasopressors all required tracheal intubation within the first $24 \mathrm{~h}$ after ICU admission. In our study, the presence of at least another organ failure and, more specifically, hemodynamic dysfunction was associated in the univariate analysis with HFNC failure. It failed to reach statistical significance in the multivariate analysis, possibly due to a lack of power. This is a clear message for those wishing to develop use of HFNC in their ICU for very hypoxemic patients such as ARDS: the presence of an additional organ failure in a patient with respiratory distress should guide the choice toward another form of ventilatory support, namely invasive mechanical ventilation. These patients may still, however, benefit from HFNC as a means to ensure pre-oxygenation. An advantage of HFNC during intubation compared with noninvasive or conventional bag-valve-mask ventilation is to ensure apneic oxygenation, ${ }^{22,23}$ which may be a key issue given the limits of pre-oxygenation in ICU patients. This is the reason why we believe it not illogical to start HFNC even in those requiring prompt intubation to ensure adequate oxygenation during laryngoscopy.

The design of our study prohibits any conclusion as to whether HFNC avoided intubation in some subjects. One can speculate, however, that given the high SAPS II score, the severity of ARF, and the extreme degree of hypoxemia $\left(\mathrm{P}_{\mathrm{aO}_{2}} / \mathrm{F}_{\mathrm{IO}_{2}}<150\right)$, a larger proportion of subjects would have been intubated in the absence of HFNC. Obviously, only a randomized controlled trial can definitely settle the question. In any case, our results do provide insight into the characteristics of patients who fail HFNC. Our mortality rates for those subjects who did not require intubation (6\% and $4 \%)$ and those who did $(50 \%$ and $47 \%)$ are very similar to the rates obtained by Antonelli et al. ${ }^{2}$

\section{Strength and Limits}

Our aim was to offer clinicians not yet using HFNC an idea of how this device can be used, in particular in the setting of de novo ARF and ARDS. We believe that we were able to capture the reality of HFNC use for $1 \mathrm{y}$ in a general ICU. Obviously, the monocentric nature of the study limits the generalization of our findings. However, this is balanced by the fact that all consecutive subjects over $1 \mathrm{y}$ were studied, thus excluding patient selection. Our database (CUB-Réa) is part of a larger network used by many ICUs in Paris and its suburbs, and several articles $^{24,25}$ have already been published with the data extracted from this database, so as to prove its efficacy and reliability. Our almost identical figures for intubation requirement and mortality in both populations (HFNC failure and success) as those of Antonelli et $\mathrm{al}^{2}$ gives credit to the external validity of our data. The Berlin Definition of ARDS $^{21}$ requires a minimum PEEP level of $5 \mathrm{~cm} \mathrm{H}_{2} \mathrm{O}$. HFNC is known to provide a significant level of positive airway pressure in comparison with a standard mask when gas flow is set as low as $35 \mathrm{~L} / \mathrm{min} .{ }^{26,27}$ This pressure may reach $7.4(5.4-8.8) \mathrm{cm} \mathrm{H}_{2} \mathrm{O}$ with a $60 \mathrm{~L} / \mathrm{min}$ gas flow and mouth closed. ${ }^{28}$ During the respiratory cycle, the greatest values were measured at peak expiratory pressure. ${ }^{29} \mathrm{Be}$ cause all our subjects were managed with a $60 \mathrm{~L} / \mathrm{min}$ flow upon initiation of HFNC, one may legitimately consider that they all received positive pressure in the vicinity of $5 \mathrm{~cm} \mathrm{H}_{2} \mathrm{O}$.

\section{Conclusions}

Our study shows that HFNC can be used at all stages of ARF management, including patients with severe ARDS. In such subjects, not only did the intubation rate compare with other techniques such as NIV, but even in those who did require intubation, HFNC was used to provide oxygenation for intubation. Owing to its efficacy and its remarkable tolerance, this device is gaining popularity in a number of situations. Further studies are warranted to quantify the number of intubations avoided with this technique.

\section{REFERENCES}

1. Schnell D, Timsit JF, Darmon M, Vesin A, Goldgran-Toledano D, Dumenil AS, et al. Noninvasive mechanical ventilation in acute respiratory failure: trends in use and outcomes. Intensive Care Med 2014;40(4):582-591.

2. Antonelli M, Conti G, Esquinas A, Montini L, Maggiore SM, Bello $\mathrm{G}$, et al. A multiple-center survey on the use in clinical practice of noninvasive ventilation as a first-line intervention for acute respiratory distress syndrome. Crit Care Med 2007;35(1):18-25.

3. Hill NS, Brennan J, Garpestad E, Nava S. Noninvasive ventilation in acute respiratory failure. Crit Care Med 2007;35(10):2402-2407.

4. Carlucci A, Richard JC, Wysocki M, Lepage E, Brochard L. Noninvasive versus conventional mechanical ventilation. An epidemiologic survey. Am J Respir Crit Care Med 2001;163(4):874-880.

5. Chanques G, Constantin JM, Sauter M, Jung B, Sebbane M, Verzilli D, et al. Discomfort associated with underhumidified high-flow oxygen therapy in critically ill patients. Intensive Care Med 2009;35(6): 996-1003. 


\section{HFNC OXYGEN THERAPY IN ARDS}

6. Manley BJ, Owen LS, Doyle LW, Andersen CC, Cartwright DW, Pritchard MA, et al. High-flow nasal cannulae in very preterm infants after extubation. N Engl J Med 2013;369(15):1425-1433.

7. Ricard JD. The high flow nasal oxygen in acute respiratory failure. Minerva Anestesiol 2012;78(7):836-841.

8. Lee JH, Rehder KJ, Williford L, Cheifetz IM, Turner DA. Use of high flow nasal cannula in critically ill infants, children, and adults: a critical review of the literature. Intensive Care Med 2013;39(2):247-257.

9. Dysart K, Miller TL, Wolfson MR, Shaffer TH. Research in high flow therapy: mechanisms of action. Respir Med 2009;103(10):14001405 .

10. Sztrymf B, Messika J, Bertrand F, Hurel D, Leon R, Dreyfuss D, Ricard JD. Beneficial effects of humidified high flow nasal oxygen in critical care patients: a prospective pilot study. Intensive Care Med 2011;37(11):1780-1786.

11. Sztrymf B, Messika J, Mayot T, Lenglet H, Dreyfuss D, Ricard JD. Impact of high-flow nasal cannula oxygen therapy on intensive care unit patients with acute respiratory failure: a prospective observational study. J Crit Care 2012;27(3):324.e9-324.e13.

12. Parke RL, McGuinness SP, Eccleston ML. A preliminary randomized controlled trial to assess effectiveness of nasal high-flow oxygen in intensive care patients. Respir Care 2011;56(3):265-270.

13. Lenglet H, Sztrymf B, Leroy C, Brun P, Dreyfuss D, Ricard JD. Humidified high flow nasal oxygen during respiratory failure in the emergency department: feasibility and efficacy. Respir Care 2012; 57(11):1873-1878.

14. Boyer A, Vargas F, Delacre M, Saint-Léger M, Clouzeau B, Hilbert G, Gruson D. Prognostic impact of high-flow nasal cannula oxygen supply in an ICU patient with pulmonary fibrosis complicated by acute respiratory failure. Intensive Care Med 2011;37(3):558-559.

15. Roca O, Riera J, Torres F, Masclans JR. High-flow oxygen therapy in acute respiratory failure. Respir Care 2010;55(4):408-413.

16. Epstein AS, Hartridge-Lambert SK, Ramaker JS, Voigt LP, Portlock CS. Humidified high-flow nasal oxygen utilization in patients with cancer at Memorial Sloan-Kettering Cancer Center. J Palliat Med 2011;14(7):835-839.

17. Peters SG, Holets SR, Gay PC. High-flow nasal cannula therapy in do-not-intubate patients with hypoxemic respiratory distress. Respir Care 2013;58(4):597-600.
18. Rello J, Pérez M, Roca O, Poulakou G, Souto J, Laborda C, et al. High-flow nasal therapy in adults with severe acute respiratory infection: a cohort study in patients with 2009 influenza A/H1N1v. J Crit Care 2012;27(5):434-439.

19. Roca O, Pérez-Terán P, Masclans JR, Pérez L, Galve E, Evangelista A, Rello J. Patients with New York Heart Association class III heart failure may benefit with high flow nasal cannula supportive therapy: high flow nasal cannula in heart failure. J Crit Care 2013;28(5):741746.

20. Brochard L, Mancebo J, Wysocki M, Lofaso F, Conti G, Rauss A, et al. Noninvasive ventilation for acute exacerbations of chronic obstructive pulmonary disease. N Engl J Med 1995;333(13):817-822.

21. ARDS Definition Task Force, Ranieri VM, Rubenfeld GD, Thompson BT, Ferguson ND, Caldwell E, et al. Acute respiratory distress syndrome: the Berlin Definition. JAMA 2012;307(23):2526-2533.

22. Teller LE, Alexander CM, Frumin MJ, Gross JB. Pharyngeal insufflation of oxygen prevents arterial desaturation during apnea. Anesthesiology 1988;69(6):980-982.

23. Frumin MJ, Epstein RM, Cohen G. Apneic oxygenation in man. Anesthesiology 1959;20:789-798.

24. Annane D, Aegerter P, Jars-Guincestre MC, Guidet B. Current epidemiology of septic shock: the CUB-Rea Network. Am J Respir Crit Care Med 2003;168(2):165-172.

25. Zuber B, Tran TC, Aegerter P, Grimaldi D, Charpentier J, Guidet B, et al. Impact of case volume on survival of septic shock in patients with malignancies. Crit Care Med 2012;40(1):55-62.

26. Parke R, McGuinness S, Eccleston M. Nasal high-flow therapy delivers low level positive airway pressure. Br J Anaesth 2009;103(6): 886-890.

27. Corley A, Caruana LR, Barnett AG, Tronstad O, Fraser JF. Oxygen delivery through high-flow nasal cannulae increases end-expiratory lung volume and reduces respiratory rate in post-cardiac surgical patients. Br J Anaesth 2011;107(6):998-1004

28. Groves N, Tobin A. High flow nasal oxygen generates positive airway pressure in adult volunteers. Aust Crit Care 2007;20(4):126131

29. Parke RL, McGuinness SP. Pressures delivered by nasal high flow oxygen during all phases of the respiratory cycle. Respir Care 2013;58(10):1621-1624.

This article is approved for Continuing Respiratory Care Education credit. For information and to obtain your CRCE

(free to AARC members) visit

www.rcjournal.com

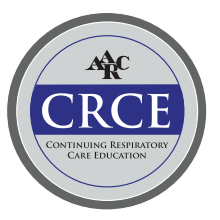

